\title{
Deontologisches aus Absurdistan
}

\section{Jann Schwarzenbach}

Dr. med., Facharzt für Allgemeinmedizin, Mitglied FMH

Erlauben Sie mir eine etwas befremdliche Frage, liebe Kolleginnen und Kollegen: Haben Sie manchmal auch das Gefühl, das Medizinerdasein sei im Grunde genommen einfach absurd? Für sich allein betrachtet, erscheinen die ärztlichen Tätigkeiten und angestrebten Ziele zwar durchaus vernünftig. So ist es beispielsweise nicht an sich absurd, zehntausende von Franken für eine einzige Behandlung auszugeben, wenn diese

Im Widerspruch zwischen dem ethischen Ideal, ganz allgemein Leiden zu lindern, und der alltäglichen Realität: Da steckt das Absurde.

dem Anspruch der Wissenschaftlichkeit genügt. Die Absurdität erscheint erst, wenn wir unseren Blick vom speziellen Fall abwenden und beginnen, uns vergleichende Gedanken zu machen: über die Tragbarkeit für unsere Solidargemeinschaft zum Beispiel oder über die vielen gesundheitlichen Probleme, die sich - mit einem ähnlichen finanziellen Aufwand und nur wenige Flugstunden von uns entfernt - in Angriff nehmen liessen. Ja, im Widerspruch zwischen dem medizinethischen Ideal, ganz allgemein Leiden zu lindern, und der alltäglichen Realität des «My patients first»: Da steckt das Absurde. Letzteres findet sich natürlich nicht nur in der Medizin. Für Albert Camus (1913-1960) wird es gar zum Paradigma der «conditio humana", der typisch menschlichen Lebenssituation, mit der sich jeder und jede Einzelne auseinandersetzen muss.

\section{Selbstbetrügerische Maskeraden}

Zunächst stellt sich aber nun die Frage, wie wir Ärzte und Ärztinnen mit dieser aufdringlichen Präsenz des Absurden in unserem Berufsfeld umgehen sollen. Wir könnten beispielsweise - vor dem ohnehin Unabänderlichen - einfach resignieren, oder noch bequemer:

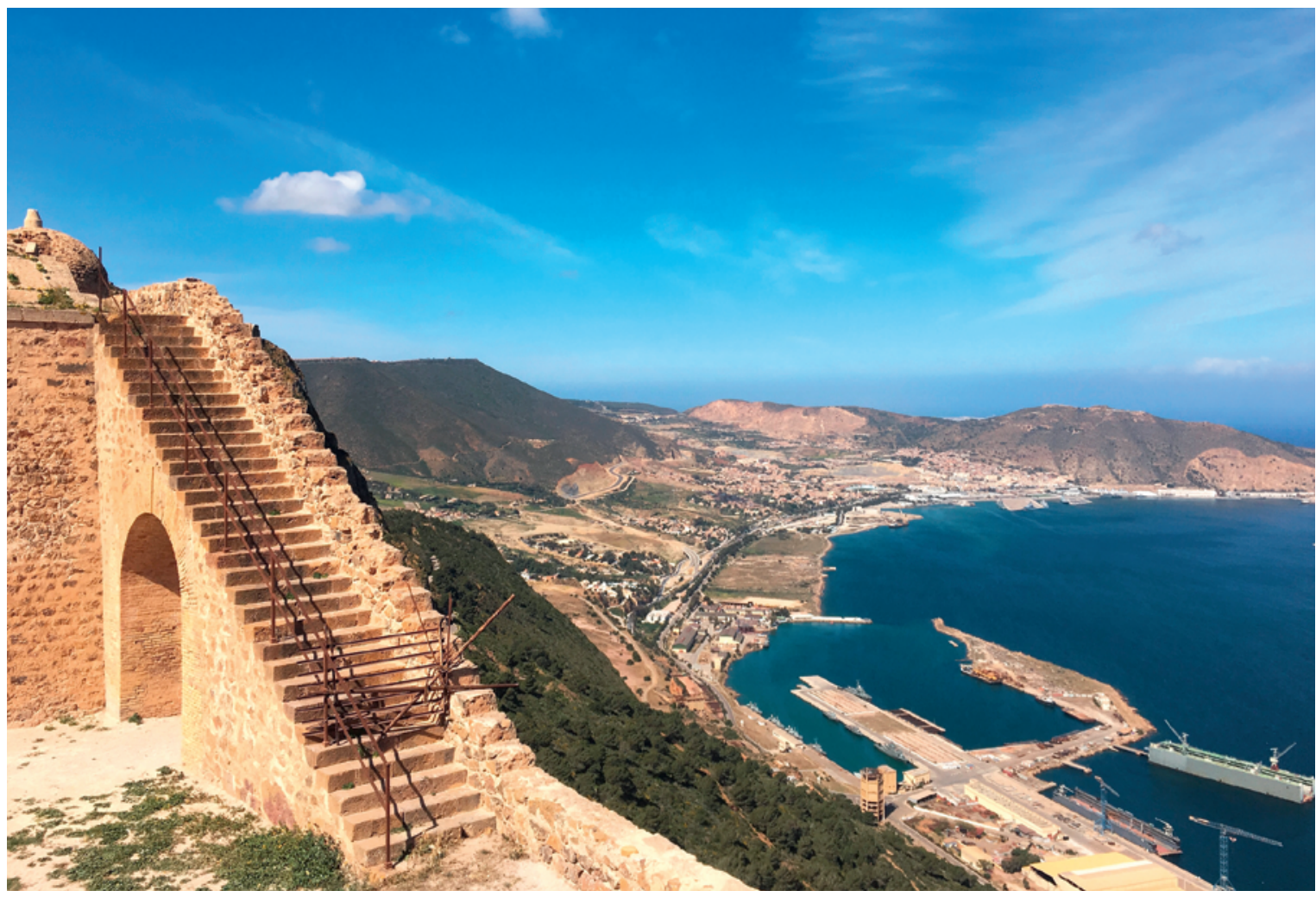

In Albert Camus' La Peste kämpft der Hausarzt Dr. Rieux in Oran gegen die unüberwindbar scheinende Pest (Blick auf das heutige Oran, (C) Runoman | Dreamstime.com). 
bei einer «höheren» Schicksalsmacht Trost einfordern. Für die Engagierteren unter uns gäbe es auch den Rückzug ins wissenschaftliche Glashaus, oder wer es sozialer haben möchte: den Versuch einer weltweiten, gerechten Verteilung unserer medizinischen Ressourcen. Für Albert Camus wären das wohl eher selbstbetrüge-

Ein Ort, wo alle Güter und persönlichen Eitelkeiten zur Farce werden und angesichts der Wut des Leidens absurd erscheinen.

rische Maskeraden, mit dem Ziel, unser Bewusstsein von der Einsicht ins Absurde freizuhalten. Das widerspräche dann eben der "conditio humana» und hiesse daher, am vollen Menschsein vorbeizugehen.

\section{Ärztliche Ethik in Reinkultur}

Um aufzuzeigen, dass es für uns Ärzte und Ärztinnen noch andere Wege gibt, der Absurdität zu begegnen, lädt uns der philosophische Schriftsteller in seine algerische Heimat ein. Dabei führt er uns zurück in die vierziger Jahre des letzten Jahrhunderts. In der Küstenstadt Oran ist das medizinische Worst-Case-Szenario eingetreten: eine Rückkehr des geschichtsträchtigen Killerbakteriums Yersinia pestis. Die Stadt wird gesundheitspolizeilich isoliert und damit zu einer klaustrophobischen Seucheninsel, wo niemand der tödlichen Willkür entgehen kann. Zu einem Ort, wo alle weltlichen Güter und persönlichen Eitelkeiten zur Farce werden und alle Ansprüche an einen «höheren" Sinn oder irgendeinen «ewigen» Wert - angesichts der Wut des Leidens - absurd erscheinen. Wir begleiten den Hausarzt Dr. Rieux bei seinen Rundgängen durch die Stadt, bei seinen Krankenbesuchen und seinen Vorsprachen bei den lokalen Behörden. Angesichts der fulminanten Ausbreitung der Epidemie verlagert sich seine Tätigkeit zunehmend von der Behandlung auf die Triage und Mitarbeit bei der Registrierung der Patienten. Trotz der hoffnungslosen Lage geht er nebst den menschlichen auch seinen intellektuellen ärztlichen Pflichten nach und engagiert sich wenn auch ohne wirklichen Erfolg - in der Suche nach einem Antiserum gegen die damals praktisch unheilbare Pest. Dem unakzeptablen Skandal menschlichen Leidens stellt er sein berufliches Pflichtgefühl in unermüdlichem Einsatz gegenüber. Obwohl er sich der Zwecklosigkeit seiner Anstrengungen bewusst ist, trotzt sein Verstand dem grausamen Gegner ohne jeden Heroismus, fern aller narzisstischen Selbstdarstellung und ohne Bemühung «ewiger Werte», «höherer» Weisheiten oder anderer Maskeraden. So reiht der
Arzt Arbeitstag an Arbeitstag und überliefert damit eine Chronik der Ereignisse in seiner Heimatstadt, die Albert Camus in der Form des Romans La Peste niedergeschrieben hat. Kalenderblatt auf Kalenderblatt, ohne Hierarchie, ohne moralische Wertungen und ohne Happy End. Viele sterben, manche überleben mit oder ohne Arzt, ohne System und ohne Sinn. Und doch: Zwischen den Zeilen, und manchmal auch explizit, tritt in diesem Absurdistan eine ganze Palette deontologischer Werte auf, wie Hilfsbereitschaft, Mitgefühl und Solidarität. Ganz unprätentiös, in nüchterner Reinform sozusagen. Frei von jedem Firlefanz, ohne moralisches "du sollst», ohne die persönliche Genugtuung "ich folge meinem Gewissen", und erst recht ohne das selbstgefällige Pathos des «guten Samariters» oder des grossen, scheinheiligen «Retters». Kein Versuch also, dem Absurden auszuweichen. Im Gegenteil: ein Humanismus beruflichen Anstandes, der unserer "conditio humana" ganz bewusst entgegentritt.

\section{«My patients first»}

Die Absurdität der menschlichen Existenz - unser Sinn- und Wertanspruch an eine Welt, die einem solchen Anspruch niemals genügt - ist für Camus eine ausgemachte Sache. Sie ist für ihn sogar die einzige, wirklich unumstössliche Gewissheit, die wir haben

Der Kollege Rieux hat aufgezeigt, dass es auch anders geht und dass - im bewussten Aushalten des Absurden - deontologische Werte aufscheinen.

können. So geht es ihm denn auch nicht primär darum, dieses Faktum aufzuzeigen, sondern eben um die Frage, wie wir damit umgehen wollen. Was die Medizin betrifft, haben wir weiter oben ein paar Optionen kennengelernt, die versuchen, das Absurde auszublenden beziehungsweise für den Einzelnen erträglicher zu machen. Nach Camus sind solche Lösungen untauglich und gehen am Leben vorbei. Der Kollege Rieux hat uns gezeigt, dass es auch anders geht und dass - im bewussten Aushalten des Absurden - sogar echte deontologische Werte aufscheinen. Er hinterlässt uns eine selbstbescheidene Chronik seiner Tätigkeit im Zeichen eines gänzlich unpopulistischen «My patients first». Viele von uns werden Albert Camus' L'Etranger im Französischunterricht begegnet sein, ohne La Peste näher kennengelernt zu haben. Das lässt sich aber ohne Weiteres nachholen. Glauben Sie mir, es lohnt sich bestimmt. Gerade im zeitgenössischen Absurdistan. 